\title{
Health Communication: Approaches, Strategies, and Ways to Sustainability on Health or Health for All
}

\author{
Patchanee Malikhao
}

\section{Contents}

57.1 What Constitutes and Has Impact on Health ............................. 1017

57.1.1 Constitution of the World Health Organization: Principles .............. 1020

57.2 Health Communication Perspectives ................................... 1021

57.3 Sustainability in Health and Health Communication ............................ 1024

57.4 Media Literacy and the Media to Assist Health Communicators for Sustainable

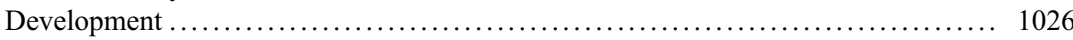

57.5 Health Communication Strategies for Sustainability .......................... 1028

57.5.1 Communication Strategies to Improve Health Through a Life Course of Empowering People ................................... 1028

57.5.2 Communication Strategies to Tackle Local Major Health Challenges of Noncommunicable Diseases, Injuries, and Violence ................. 1030

57.5.3 To Tackle Vaccine-Preventable Communicable Diseases ............... 1031

57.5.4 Communication Strategies to Tackle Non-vaccine-Preventable or Not-Yet-Vaccine-Available Communicable Diseases Such as Malaria, Dengue Fever, Tuberculosis (TB), and HIV/AIDS and Respiratory

Diseases Such as SARS, MERS, H1N1, and H5N1 ................ 1032

57.5.5 Communication Strategies to Strengthen People-Centered Health Systems, Public Health Capacity, and Emergency Preparedness, Surveillance, and Response ............................................. 1033

57.5.6 Communication Strategies to Create Resilient Communities and Supportive Environments, Including a Healthy Physical Environment .............. 1034

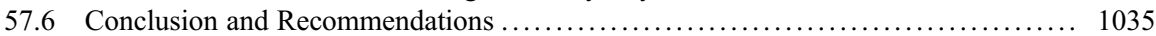

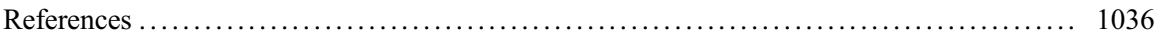

\footnotetext{
P. Malikhao $(\square)$

Fecund Communication, Chiang Mai, Thailand

e-mail: pmalikhao@gmail.com
} 


\section{Abstract}

This chapter starts from a holistic perspective on health in the society. It makes a statement that, in order to become effective and sustainable, health communication needs to be studied, assessed, and practiced from a rights- or social justicebased position. Such an approach implies the use and integration of multidisciplinary perspectives that try to grasp the complexity of health issues from both global and local, individual, interpersonal, group, and community levels.

\section{Keywords}

Health for all $\cdot$ Wellness $\cdot$ Well-being $\cdot$ Health behavior $\cdot$ Communication strategies · Health literacy · Intercultural communication · Media literacy · Participatory media $\cdot$ Community media $\cdot$ New media

Health is a core element in people's well-being and happiness. Health is an important enabler and a prerequisite for a person's ability to reach his/her goals and aspirations, and for society to reach many of the societal goals (Minister of Social Affairs and Health, Finland, 2013: 3).

Health communication has been a part of development communication or communication for development for the past five decades. Royal Colle (2003: 44-51) explains that health communication has been one of the threads of development communication together with population information, education, and communication (IEC) since 1969. Then, it was concerned with population and family planning programs, with an emphasis on reproductive health that includes family planning, maternal and infant death and disability prevention, sexually transmitted diseases (STD) and HIV/AIDS prevention, harmful cultural practices such as female genital mutilation (FGM), violence against females, human trafficking, and female health (Colle 2003: 46).In her book, Effective Health Communication for Sustainable Development, Patchanee Malikhao (2016: 6-7) explains how the history of health communication, as a separate field of study, has emerged from being only a part of health education and training in medical and public health to the integration of health-related aspects of individuals, communities, and organizations or their environment, with appropriate communication and mass communication theories. These communication theories borrow models and frameworks from (1) social science fields such as psychology, social psychology, anthropology, and sociology; (2) humanities subjects such as culture, linguistics, and languages; (3) ecological and environmental science; and (4) medical science fields.

Today health communication has expanded its scope from biomedical interventions at a personal level to more context-based communication about health, which includes the socials and the environment that have impacts on an individual's health. Robert Rattle (2010: 130-141) affirms that these are the social determinants of health, apart from the physical determinants, and above all the health policies that impact health behaviors. 


\subsection{What Constitutes and Has Impact on Health}

Let's try to understand what constitutes health before we discuss what determines good health. Some scholars think that health means only the absence of disease or infirmity. That is not enough, because, during our life course, we all experience discomfort, disabilities, and pains along the way, such as child teething, babies being unable to act as adults do, women having menstruation pain or having labor pain, and certain conditions such as pregnancy (Janzen 2002: 69). These kinds of pain do not indicate that we are not healthy. Janzen (2002: 69) also includes aging, fatigue, birth impairs, and growth disorders as diseases. Our individual health is indeed hardwired with intrinsic diseases, pains, and discomforts. It is a fact of life! Each individual is subject to different healthy degrees, depending upon the physical determinants of health - the physical environment, biology and genetic endowment, and medical service (Rattle 2013: 181). A twin, who lives in a good and clean environment where medical service is well-organized, would be healthier than the other twin who lives in a polluted environment with poor medical service. New medicines and vaccines could save lives, but some people can get access to these innovations easier than others.

Some people are born with birth defects and that makes them less advantageous than others. Some people inherited genes from their ancestors which makes them prone to high blood pressure, diabetes, anemia, etc.

How we think, feel, cope with issues, and manage our life should not be neglected. That is how we differentiate the terms "well-being" from "wellness." Wellness is more related to the physical abilities of a person to perform tasks up to the full potential (Dunn 1977: 9-16), but well-being indicates that there are intangible elements that we cannot miss out. We therefore need to look at other dimensions of health apart from focusing on only our physical health: fitness, agility, body mass index, etc. That's why Hunter, Marshall, Corcoran, and Leeder (2013) categorize four aspects of health: (a) psychological/emotional, which includes positive attitudes, awareness, resilience, etc.; (b) intellectual/cognitive, which constitutes the ability to learn and to be creative and critical; (c) spiritual, which includes one's values and beliefs, a sense of meaning and purpose in life, inner peace, and an ability to transcend one's own self, and occupational, which means the satisfaction from working unpaid or paid and recreational activities; and (d) environmental.

Rattle (2010: 190) explains that there are eight factors in the socials that have impacts on our health. They are relative income and socioeconomic status, education, employment and working conditions, social support networks, health practices and coping skills, healthy child development, culture, and gender. All of these are socially constructed, which means that it is shaped by our interactions with others within the context we live.

People with higher incomes seem to have a higher education, and those with higher socioeconomic status can afford private health insurance and have regular health checkups. People with a higher income tend to live in a safer neighborhood and do not face depression that is often the result of living in unsafe public spaces. Those with better incomes can enjoy better outdoor life with access to more sports facilities and 
recreation. Better income guarantees hygienic sanitation and healthier living conditions that could prevent respiratory diseases, health hazards, and epidemics.

Better education would result in better personal hygiene and better access to knowledge on diseases and their prevention. Better education is closely related to meaningful job opportunities which in turn brings in satisfaction/self-contentment, inner peace, self-esteem, and self-control/self-power/self-autonomy among other life qualities (Mirowsky et al. 2000: 50-56). Moreover, good working conditions will prevent employees from hazards and bad physical conditions caused by a nonsafe environment.

People with good social networks can get more access to self-help medical knowledge, health practices, and have a better basic knowledge of hygiene and sanitation, first aid, vaccinations, etc. With social supports, an individual benefits from inner peace and is better able to cope with traumatic experiences and loss.

Healthy childhood development depends upon the socioeconomic status of the parents and the health-care services within the community. One can notice a higher mortality at birth, poorer overall health, and the development of chronic illnesses in adulthood among individuals from a lower socioeconomic status (Sarafino 2006: 158).

Culture is socially constructed and dynamic. It is what we pass on from generation to generation. It influences the way we interact and how we experience the world, including suffering, pain and its articulation, healing, mental health, and selfhelp. According to Brown (1995: 8-9), the tangible aspects of culture can be seen as artifacts, norms and behaviors, heroes and symbols, the media, languages and expressions, stories, myths, jokes, rites and rituals, ceremonies, and celebrations. Its intangible aspects are beliefs, values, attitudes, and the worldviews of people. The worldviews of people in different cultures are influenced mostly by their religion and beliefs (Malikhao 2016: 78). In Caring for Patients from Different Cultures, Galanti (2008) explains at length how different cultures, influenced by different belief systems and religions, affect the way people express pain and suffering, perceive and discuss mental health, perform healing practices, develop culturally bound syndromes, and organize support networks.

Now it comes to the last social determinant: gender. Gender is socially constructed as well. Males seem to have more social burdens than females, as more males are still expected to be the breadwinners. They tend to be more stressed than females and use more drugs, tobacco, and alcohol to cope with stress (Malikhao 2016: 72).

It is worth noting that the physical and social determinants can be intertwined, and induce cross-link effects, and that can be messed up with biological determinants such as age, sex, and more importantly the genes or our DNAs and the lifestyle of the people in this postmodern era. All of that makes an individual's health different from one another. Pollard (2008) explains in her book, Western Diseases: An Evolutionary Perspective, how our genes adjusted themselves when people changed their lifestyle and dietary pattern from the East to the West, and that caused the so-called Western diseases or noncommunicable diseases such as type 2 diabetes and colon and breast cancer among other diseases mostly found as the cause of death among people in the Western world North America, Western Europe, Australia, and New Zealand. Pollard states clearly in her book that the Western diseases are also found among the rich populations in the Third World as a result of imitating the lifestyle of those living in the West. This can be 
explained with the term "aberrant epigenetics." It means that a change in the environment and/or change of dietary patterns in an early stage of life could have an impact on the DNA of our cells, not as much to alter the genetic makeup of our body but enough to cause certain diseases such as Alzheimer, schizophrenia, asthma, and autism (Marchlewicz et al. 2015:4). Western diseases are one of many indicators of how globalization affects the health of the world population. Postcolonial or contemporary globalization has been speeded up in both degree and kind by advances of information and communication technologies (ICT). The moving of labor, goods, production sources, technology, etc., with driving forces such as the marketing and advertising industry across the globe, results in unequal affluence and instigates new patterns of consumption and lifestyle and new diseases and the comeback of almost eradicated diseases (Lee 2005: 14; The College of Physicians of Philadelphia 2018; CDC 2010, 2014; Emedicinehealth.com 2018). To elaborate, some parts of the world or sectors within the same country benefit from globalization more than others, which causes unequal opportunities in accessing basic needs for city dwellers: clean water supply, proper sanitation, waste disposal, proper housing, clean air, public playgrounds, good schools, good working conditions, adequate primary health-care services, or a good marketplace that provides fresh, clean, and nutritious foods. Respiratory diseases; dysentery diseases; tuberculosis; plague; depression; mental health and health issues due to tobacco, drugs, and alcohol use; and other epidemics happen more in less developed, mainly crowded areas. As more and more people migrate in pursuit of better opportunities, communicable diseases could spread far and wide. Patchanee Malikhao explains at length in her 2012 book, Sex in the Village: Culture, Religion and HIV/AIDS in Thailand, how the pandemic HIV/AIDS occurred due to a complex factors including migration of labor, unsafe sex practices, the change of sexual norms due to globalization, discourses on safe sex education, HIV/AIDS prevention public health policies, the localization of the global HIV/AIDS prevention, discourses on the religious HIV/AIDS interventions, gender inequality, and poverty to name a few (Malikhao 2012).

As people have more sedentary lifestyles, triggered by using automations and performing white-collar work, together with eating fast food and processed food that contains too much sugar, salt, and fat, they are prone to develop noncommunicable diseases (obesity, cardiovascular diseases, diabetes, among others) (Lee 2005: 14).

Globalization brings in advantages and disadvantages in disease prevention and eradication. Malikhao (2016: 51-52) reports the resurgence of diseases that broke out because either the bacteria have become antibiotic-resistant (such as avian influenza, cholera, influenza, and chikungunya) or there have been cross-links between the virus that used to cause diseases in animals in previous days with that used to cause diseases in humans resulting in new hybrid diseases such as mad cow disease, bird flu, or swine flu. At the same time, thanks to vaccinations, certain diseases such as small pox and rinderpest have been wiped out, and some diseases such as polio, measles, and mumps are on the way to die out.

Malikhao $(2016: 51,52,55,112)$ reports that, in a developed world, the haves are not much healthier than the have-nots; some people face health problems such as stress, anxiety, depression, burn out, sleep deprivation, obesity, or risk-taking behaviors such as 
smoking, alcohol abuse, and drug addictions due to unemployment and underemployment. The developed world can impose more health threats to the less developed world by exporting, in the name of advertising and marketing, unhealthy products such as tobacco, alcohol, fast food, chemical waste, etc. While, in the developing world, some people face starvation due to poverty, some in the developed world develop eating disorders such as anorexia nervosa and bulimia as a result of the change in perception of one's self-image, partly due to the complexity of mediatization (change of social interactions modulated by the media - Hjarvard 2013: 17), mediation, and new forms of individualization with symptoms of depression, anguish, apprehension, and anxiety found among the haves (affluenza) in the contemporary globalization period (Lemert and Elliot 2006; Twenge and Campbell 2010; James 2007).

Above all health policies of each state or country do influence the health behaviors of a population in major ways (Rattle 2010: 141). That includes the foodproducing and food-marketing industry which has strong relations with the politico-economic and legal systems and the public health policy of a country. Pesticides, insecticides, hormones, antibiotics, and controls in the agriculture and food industries would benefit the health of the consumers a great deal. Moreover, the systems of health-care services are also determined by the public health policy of a country. Malikhao (2016: 80-81) uncovered four basic health-care systems in the world, as presented on the PBS Frontline documentary in 2015:

1. The Beveridge model. It is a government model that supports the health system totally with the tax payers' money. It is used in Great Britain, Hong Kong, Spain, most of Scandinavia, and New Zealand.

2. The Bismarck model. It is a nonprofit model in which health care is privately funded by payroll deduction of employees and funded by the employers. It is used in Germany, Japan, Belgium, the Netherlands, France, Switzerland, and somewhat in Latin America.

3. The National Health Insurance model. It is a model funded by a governmentadministered insurance program through private providers. It is used in Taiwan and South Korea.

4. The out-of-pocket model. This is used in the USA. It is the nonmedical care for the have-nots and medical care for the haves.

Having said all of that about health, one could not agree more with the definition of health principles in the constitution of the World Health Organization (WHO 2018a).

\subsubsection{Constitution of the World Health Organization: Principles}

Health is a state of complete physical, mental, and social well-being and not merely the absence of disease or infirmity.

The enjoyment of the highest attainable standard of health is one of the fundamental rights of every human being without distinction of race, religion, political belief, and economic or social condition. 
The health of all people is fundamental to the attainment of peace and security and is dependent on the fullest cooperation of individuals and states.

The achievement of any state in the promotion and protection of health is of value to all.

Unequal development in different countries in the promotion of health and control of diseases, especially communicable disease, is a common danger.

Healthy development of the child is of basic importance; the ability to live harmoniously in a changing total environment is essential to such development.

The extension to all people of the benefits of medical, psychological, and related knowledge is essential to the fullest attainment of health.

Informed opinion and active cooperation on the part of the public are of the utmost importance in the improvement of the health of the people.

Governments have a responsibility for the health of their people which can be fulfilled only by the provision of adequate health and social measures.

The Constitution was adopted by the International Health Conference held in New York from June 19 to July 22, 1946, signed on July 22, 1946, by the representatives of 61 states and entered into force on April 07, 1948. Later amendments are incorporated into this text."

The WHO acknowledges the multidimensional nature of health, that health involves complete physical, mental, and social well-being and not just the absence of disease. Moreover, everyone has the right to maintain and enjoy the benefits of being healthy regardless of their socioeconomic-politico and religious status. That means everyone has the right to medical, psychological, and related knowledge necessary to attain health to the fullest capacity. The health inequality caused by unequal development should be attended to by each government. Each government should be responsible for the health of their population by providing appropriate health and social measures.

We can draw three important notions from the constitution of the WHO: that "rights to health care," "health inequality reduction," and "health for all" are essential to devise good communication strategies to achieve the health goal. This leads to the next topic.

\subsection{Health Communication Perspectives}

In the 1980s and early 1990s, health communication was known as a form of health education and health promotion and preventive medicine and focused on communication at many levels (interpersonal and organizational communication) in healthcare settings. Mainly in the USA, but also in the UK, the focus was even more down to communication among the patients and the health-care provider (Lupton 1994: 56; Irwin 1989: 32, 40).

Health communication theories that originated in the USA have focused on mainstream quantitative research perspectives for about four decades. Malikhao (2016: 19-26) reports that these theories are borrowed from the fields of psychology and social psychology, which emphasize cognitive and behavioral changes at the 
intrapersonal, interpersonal, and group/organizational level. Popular models for intrapersonal communication are, for instance, the health belief model, theory of reasoned action (TRA), theory of planned behavior (TPB), the integrated behavioral model (IBM), the transtheoretical model and stages of change (TTM), and the precaution adoption process model (PAPM). Models used for interpersonal communication are social cognitive theory (SCT) or social learning theory (SLT). Models used for organizational communication are stage theory of organizational change, diffusion of innovation, and social marketing and edutainment.

Malikhao (2016: 16-17) reports that the signature of these kinds of models is that they rely heavily on positivism which is based on natural science models of cause and effect. They flatten the well-rounded facts of life into a linear line for prediction with inferential statistics. The models used for intrapersonal communication seem to assume direct relationships between knowledge, attitude, and behavior regardless of the context within which people live. The models used for interpersonal communication pay attention to the simplicity of the stimulusresponse formula and the modifications of it, such as Laswell (1948) formula, "Who? Says what? Through which channel? To whom? With what effect?" and Katz and Lazarfeld (1955) two-step flow of communication, which relays on the spreading of messages from opinion leaders received via the mass communication to other people. Moreover, at the societal level, these models focus on the ability of humans to act in stages from being laggards to people who adopt innovation completely. However, they pay less attention to the socio-politico-cultural context that impinges on the ability to change those individuals. The organizational models assume the one-fit-all models and technology transfer from a more developed country to a less developed country.

These American-based models are built under the modernization paradigm which assumes that the Western way of living is a desirable goal for development everywhere. It is a positivist perspective that emphasizes empirical observations and statistics. Health communication within the modernization paradigm involves a high-tech, top-down, and unilinear approach from health professionals either directly or through the mass media to the receivers aiming to educate, upgrade, or train them to be informed in public health, have good attitude toward biomedical interventions or health-related advice/information, and have self-efficacy to change health-risk behaviors to a healthy lifestyle and health behaviors.

The modernization paradigm has been challenged since the 1990s in the multiplicity paradigm proposed by Servaes (1999). This paradigm is more than a manyroads-lead-to-Rome approach as one can go by foot, by plane, or by boat and one can mobilize others to join them to Rome without having to listen to the commands from Rome. Health communication within this paradigm emphasizes human rights: freedom from exploitation, the right to access adequate health care and health insurance, equity, community efficacy to come up with one's own solutions to manage resources and health 4 issues, participatory democracy, and sustainability in health or health for all in a given socioeconomic and cultural system at all geopolitical levels. With the help of the new media (which is going to be elaborated in the next section), the dream of managing community health and disease prevention by the people and for the people has come true. 
Malikhao (2016: 31-40) researches communication perspectives within the framework of the multiplicity paradigm at the individual level, interpersonal level, and group or community level:

At the individual level, the Self Determination Theory of SDT by Ryan and Deci (2002:5) is preferred. This theory focuses on the context where an individual lives or the extrinsic factors that motivate that person to motivate oneself to engage in behavioral change. The internalization process of a person comes from having opportunities to make a choice that is meaningful to oneself in the socialization process and receive a positive feedback to encourage the change of behavior. That means one cannot change his/her behavior by just receiving messages, one has to have an enabling environment to foster desirable health behaviors.

At the interpersonal level, life skill training and education are essential to build up intrinsic factors of an individual to prevent health risk behaviors and health hazards. Intercultural competency training is important for health care professionals to empathize patients and people in the community.

At a group/community level, some social capitals such as support groups and peers together with positive rewards can help reinforce the change of habits into desirable ones. Theories of social network and social support, community organization and community building theories as well as the PRECEDE/PROCEED Model and the Ecological Models of Health Behavior are having common characteristics of enabling environment, including advocacy communication, participatory communication, communication for structural and sustainable social change. Advocacy communication for health is about using the mass media to empower the voiceless to be heard regarding health hazards, issues on environment, and health-related issues. Participatory communication for health enables the locals, regardless of sociocultural and politico-economic status, to act and have dialogues in a democratic way to discuss and prevent diseases, hazards, and pollutions, and promote healthy life style, safety and clean environment. Participatory-based advocacy diversifies advocacy communication by adding the idea that the locals could get together and manage the content of the mass media used to advocate solutions on health issues, pollution, hazards, and clean environment. Health communication for structural and sustainable social change uses mix and match approaches, to advocate change and participation according to the situation, felt-needs of the locals, the budget, and available resources. A health communicator in the Multiplicity Paradigm can be called a social mobilizer who cultivates his/her attitude to empathize with others to achieve capacity building and empowerment and be able to mobilize the community to research, plan, and execute projects that are useful for the sustainability on health of the community (Malikhao 2016: 99).

All of these models in both paradigms have been used by many scholars for research. According to Babrow and Mattson (2003: 47-53), based on Craig (1999), historic traditions of research on health communication can be summarized under seven categories:

- The rhetoric tradition focuses on how the health communicators persuade the policymakers to act upon health projects.

- The semiotic tradition pays attention on how health communicators are mediated in intersubjectivity fashions by signs and sign systems. 
- The phenomenological tradition studies an individual's and others' health experiences in the process of the patient and health-care provider communication.

- The cybernetic tradition looks at the process of health communication in linearity, which implies the encoding of a message, the transmission of the data, decoding of the data, feedback, and the impact on the environment.

- The sociopsychological tradition is about what affects the cognition, emotion, and behaviors of an individual when she/he interacts with the socials.

- The sociocultural tradition studies how health communication produces new sociocultural patterns which have been shared.

- The critical tradition relies on the critical theory used to study discursive reflection of health and illness.

The interdisciplinary research on health communication encourages to gain rich, insightful, and meaningful data to accompany the empirical observations.

\subsection{Sustainability in Health and Health Communication}

Sustainability is what many people talk about in this postmodern era. It seems as if one realizes that, within the limited resources on Mother Earth, we should manage, conserve, and nurture our own habitat in line with an ecological balance, so that new generations to come can enjoy it as well. That is only one part to reach sustainability. Apart from having a healthy environment, we should consider a healthy social (social justice) and healthy economy as sustainability as a whole (Cox and Pezzullo 2016: 264). Sustainable development implies five different areas that we need to pay attention to: water and sanitation, energy, human health, agricultural productivity, and biodiversity and ecosystem management (Wallington 2014: 170).

Sustainability on health is to uplift equality of the quality of life for everyone. Poverty, discrimination, less opportunities to get education and employment, living in substandard housing and environment, and less opportunity to access primary health care are the underlying assumptions of inequality in health. According to Malikhao (2016: 99), sustainability on health is a process of social mobilization empowered by both stakeholders, some of whom can be health communicators, and health communicators from outside who have empathy toward the stakeholders, to achieve two goals: first, to engage the people in the community in upgrading the health and media literacy status so that they can make an informed choice on their body and health and health care and, second, to build up community capacity and networking with other communities so that the people can solve problems related to community health, achieve social justice in health, prevent diseases, maintain well-being, and cultivate health knowledge, good attitude, ethical values, cosmopolitan worldview, and health behaviors, including advocating for structural change for a local healthy lifestyle and accommodating environment. In addition, we should call for a rights-based health communication which means everyone should have the equal right to access primary health care regardless of his/her socioeconomic status. We should cultivate intrinsic values, such as self-contentment to instill inner peace that is opposite to short-term pleasure from mindless consumption triggered by the advertisement and marketing industry. Moreover, we should economize 
on natural resources and energy consumption, including the reduction of carbon footprints to prevent the acceleration of global warming. Extrinsic factors are those that enable people to think, rethink, assess own and community values, empower themselves to improve one's own health, and participate to improve community health. They are families; schools; communities; the governmental sectors related to public health, energy, and the environment; the NGOs related to health and environment; the mass media and new media; man-made environment; and natural habitats.

Health communication advocating for sustainability ought to be operating under the framework of the multiplicity paradigm mentioned above. To achieve the status of "health for all," "rights to health care," and "health inequality reduction," the integration of five different approaches is needed: behavioral change communication, mass communication, advocacy communication, participatory communication, and communication for structural and communication change. The recipes for each case vary according to each setting, but we can summarize what Patchanee Malikhao suggests in the section of Communicating for/about Health for Sustainable Development in her book, Effective Health Communication for Sustainable Development (Malikhao 2016):

Behavioral Change Communication for Health for All is about interpersonal communication on health literacy, health control and management, disease prevention, food and nutrition, wellness and well-being, etc. The main aim is to engage the stakeholder to become a health agency who has an autonomy of own health and can make informed decision. The media used can be both the mass media of the new media that encourage social supports.

Mass Communication for Health for All is about using the mass media convergence to empower the stakeholders and ease the participation process in addressing a health problem in a community. The mass media convergence is the ability of the modern mass media, thanks to the new media, to have more platforms that can interact among one another. For instance, a newspaper can have a digital TV channel, a Facebook page, an Instagram page, a Twitter channel, and a website which allows the audience to follow life video/audio clips or stock audio files for podcast or stock video clips to be watch on a laptop, smartphones, or digital TV screen. Media literacy should be as important as health literacy for health communicators.

Participatory-Based Advocacy Communication for Health for All means empowering the grassroots to interact with key decision-makers on health issues aiming at influencing them to support policy changes at all levels (and also international) and to sustain accountability and commitment from governmental and international actors (WHO 2018b; Servaes and Malikhao 2010: 43).

Participatory Communication for Health for All employs both interpersonal communication and multi-community media as well as social media to cultivate community interests and participation, by taking diversity and pluralism into account, in health-related areas. Participatory social marketing on health is the added values on the traditional social marketing to communicate about/on health. That can be both online and offline campaigns using the social interconnectedness online and face-to-face dialogues to buzz news, information, events, and other social media entries. Self-management and production of the media and access of both media producers and stakeholders are emphasized (Berrigan 1979: 8). 
Communication for Structural and Sustainable Social Change for Health for All is a combination of all of the above approaches to empower the stakeholders to upgrade and advocate for their own and community health on correct information on health, health and media literacy, disease prevention, environmental health, health behavior, and access to affordable and quality health-care system.

In order to achieve sustainability, health communicators should possess essential knowledge and skills of intercultural communication. Malikhao (2016: 102-105), adapting from the framework of Martin and Nakayama (2010: 50-52), elaborates on intercultural competency in health in five aspects: First, understanding personal and contextual way of communication. Health communicators should be able to discern personal health behavior (such as brushing teeth two times daily) from the behaviors that are results of social construction (such as sharing syringes among prisoners).

Second, understanding the differences and similarities between cultures. People from different cultures may have different ways in verbal and nonverbal communication. Pain expression, treatment option, or healing rituals can be different from culture to culture. The similarities are obvious that everyone needs respect, kindness, and a nonjudgmental attitude.

Third, understand the local cultural context in which we are operating. If the health communicators can speak the local language, it would be a plus to create rapport between them and the stakeholders. Understanding one's own culture and biases in one's own culture, but at the same time having sensitivity to other cultures and appreciation for the differences, should be the characteristics of health communicators (Galanti 2008: 2).

Fourth, understanding the privilege and disadvantage in the socials. Health communicators have advantages in the sense that they may have good connections with the community leaders and policymakers and they may already know the strengths and weaknesses of the community. But they may face resistance from the stakeholders. They may need to step back and assess the situation.

Fifth, history and past understanding. Knowing the history of the health situation of the unit of analysis is important to assess the present situation and plan ahead. The unit of analysis varies from small to large: individual, family, ethnic group, group, community, institution, or a country.

Next, we need to understand the media, especially the new media, to assist health communicators to do the right job.

\subsection{Media Literacy and the Media to Assist Health Communicators for Sustainable Development}

As summarized from Malikhao (2016: 109-123), it should be clarified here that the media is not the message, but the type, format, and limitation of each medium shape the content of the messages. In our mediated world, fueled by digitization, no matter whether we like it or not, we are in the process of mass self-communication, a term coined by Castells (2013: 55), as we are parts of a digital network. We are using the new media every day. According to Fuchs and Sandoval (2015: 165), new media are the media that are based on the World Wide Web, which includes social networking sites such as Line, WhatsApp, 
Facebook, etc., or video-sharing sites such as YouTube, Vimeo, etc. They can be wikis or a website on which users are allowed to modify the text from the web browser in collaboration with others such as Wikipedia. They can be blogs such as Blogspot, WordPress, etc. or microblogs such as Twitter and Sina Weibo. They can be online pinboards such as Tumblr and Pinterest. They can be a photo-sharing site such as Instagram. While sending texts that we create and sharing images and motion images we create ourselves or repost from someone else, with friends and our circles or networks of contacts, we are acting as both an interpersonal and a mass communicator.

Hence, the term mass self-communication is quite handy to describe our way of communication. Mediation was the old term, that we are mediated by mostly traditional media (newspaper, radio, television, or the classic media) as well as the new media or alternative media such as Indy media (or independent media - which are the media that do not aim for commercial profits and tend to stand up for the underdogs). However, there is another term coined by Hjarvard (2013: 17): mediatization, that is, the long-term influence of mediation creates changes in the culture and institution. Mediatization makes contacts across the globe a reality, makes people think about their identity, and creates digital divides, meaning the gap between those who can access the new media and those who cannot is wider (Martin and Nakayama 2004: 6).

Let's discuss the concept of "media literacy," which any health communicator should understand apart from being a health literate. As summarized from Turow (2014: 20-21), a health communicator should know that, first of all, media are not the reflection of a reality. Media are constructed, constrained, and influenced by those who produce them and the media business owners. Second, media are related to power and profits. The larger the company, the more power it has to media convergence, more power to control the entire process of media making, and more chances to dominate other cultures with the media products as cultural products: that is called the "soft power." Third, the media contents are shaped by a political ideology, worldview, and values of the creators. Fourth, the format of the media shapes the characteristics of the media. Fifth, different audiences interpret the same media message in different ways due to their own worldview, background, and education. Sixth, each medium is unique aesthetically. Seventh, the media are the mirror of the visions in society.

Media literacy can be categorized further into four different subgroups, explains Share (2015: 192-197): visual, aural, multimedia, and alternative literacy. Do keep in mind that different lighting, lenses used, types of cameras, camera angles, distances between objects and cameras, and so forth create a different visual image. Aural literacy makes us aware that the same sentence that was spoken and heard in a different context will convey different messages. Multimedia literacy calls for the understanding and capability in the process of making multimedia from the beginning to the end. Alternative literacy calls for the ability to analyze the mainstream media how they create hegemony, how the main stream media represent the power from the dominant ideology, and how to represent underserved perspectives.

The alternative to the mainstream media is community media (Carpentier et al. 2012). They can assist health communicators to become health mobilizers. They can help raise awareness, amplify, and engage the stakeholders and solicit solutions or immediate response from the community. These media can be community radio, community television, community video, community-based telematics systems, or just a community 
folk media, or the same old print media that can be displayed at the places where people gather together temporarily, such as a fair, or permanently, such as in a railway station.

Community new media offer interactive responses. They can be various media, such as telemedicine technology, e-health, Internet radio, Internet television, geographic information system (GIS), and Webs 2.0, 3.0, and 4.0, which allow a community website or community social media platform where everyone can exchange information and voice his/her concerns on health-related areas, environment, and well-being of the community. This author would like to call them participatory new media.

\subsection{Health Communication Strategies for Sustainability}

Stakeholder analysis, recognizing and defining the public health problem, setting goals and objectives, identifying resources, and maintaining control of the problem are steps useful for participatory action research on health-related issues (Malikhao 2016: 127).

According to the WHO Europe (2013), to achieve sustainability in health, these strategies can be categorized fourfold:

1. To improve health through a life course of empowering people.

2. To tackle local major health challenges of noncommunicable diseases, injuries and violence, and communicable diseases.

3. To strengthen people-centered health systems, public health capacity, and emergency preparedness, surveillance, and response.

4. Communication strategies to create resilient communities and supportive environments, including a healthy physical environment.

Malikhao (2016: 143-164) Modifies the abovementioned strategies by introducing the integration of five different approaches: Behavioral change communication, mass communication, advocacy communication, participatory communication, and communication for structural and communication change health communication but with a stress on the last three approaches. The integration of traditional media, new media, and/or alternative media is possible depending on cases. In order to come up with tangible strategies, we should keep in mind that women development must come first in order that they can bring up their children (WHO Europe 2013: 73-74). Then, we can focus on children and adolescent, adult, and elderly health.

\subsubsection{Communication Strategies to Improve Health Through a Life Course of Empowering People}

In all of these age groups there are similar strategies aiming at an individual level, a group level, and structural level. The following communication strategies are summarized from Malikhao (2016: 144-153), aiming to improve on health quality at an individual level: 
- Inviting stakeholders to a training program on health and media literacy via a community website or letter, emails, tweeting, phone calls, leaflet distribution, posters, and messages on social media applications and on cell phones.

- Promoting health education on sex education, communicable and noncommunicable diseases, and rights and justice, for the female group and each age group in public institutions, and by using folk media and community media.

- Promoting information on female health and each age group's health on social media, community media, and the mass media. The community website can be created with built-in podcasts, vodcasts, links to YouTube videos, and links to urls that give information on gender equality, reproductive health, healthy lifestyle, parental skills, preventive information on diseases, clean environment and sanitation, dementia and mental health, etc.

- Raising awareness for routine immunization program for each age group by using emails, letters, posters, blogs, websites, twitter, and community folk media.

- Promoting the inclusion of females, people from each age group, and people from other ethnic groups in any community event.

- Promoting values for healthy lifestyles and advocating for an alcohol-, smoke-, and drug-free life on new community media such as blogs, websites, podcast, digital storytelling, and community media such as theater plays, posters, banners, walls, community radio and TV, social media, and the mass media.

- Promoting nonviolent and nondiscriminating ways to solve problems by using digital storytelling, theater plays, podcast, community radio, and TV.

- Using personal contacts can help unlearn undesirable health behavior like eating fast food and consuming sugary drinks and replace old habits with new habits of eating fresh vegetables, whole grains, and fruit, exercising, and diet control. A workshop and a follow-up program can be designed to accommodate offline discussions.

- Promoting benefits of living in good and clean housing, settings, and environment by using video clips shared in the social media as well as mobile exhibitions with videos and digital storytelling.

The following are communication strategies that aim at improving health quality at a group level:

- Advocating for a school-based curriculum on media and health literacy and courses on media and health literacy in college.

- Advocating for a school-based sex education which includes respect for female rights, gender equality, sexual debut, contraception, and STD and HIV/AIDS prevention.

- Training health-care and medical personnel and interested stakeholders media literacy, communication, and digital media skills. Promoting the training courses can be done by using traditional media as well as the new media.

- Using participatory community media to air information on many topics such as maternal health, teens and adolescent forums, family planning, parenting skills, etc.

- Facilitating collaborating among families, age groups, and members in a community by producing participatory video clips or vodcasts on healthy lifestyle for teens, tweens, adults, the elderly, pregnant women, etc. 
- Forming a peer-to-peer online and offline group to exchange views and information on maternal health, mental health, adolescent health, elderly health, etc. brainstorming sessions are recommended to come up with cue, routine, and reward for building up healthy lifestyle such as eating fresh vegetable and fruit, exercising, etc. filming the sessions and upload video clips on the community website or air them on the community media.

- Organizing an online or offline group on preventing alcohol and substance abuse among women and other age groups.

- Participating in the evaluation of all programs and coming up with recommendations and plans for improvement.

The following are communication strategies that aim at improving health quality at a structural level:

- Advocating for rights of the women, children, and the elderly. Video clips made by the collaboration of community members are encouraged to tackle on a particular issue. Sending those clips to the public health authorities and writing articles about these rights on websites, social networking pages, and blogs are recommended.

- Advocating for improving of women and men education. This includes antidomestic violence and rapes. Digital storytelling or interview clips of women in the community can be displayed on diverse social media platforms.

- Advocating for the equality of men and women in employment and organizing media campaigns to raise awareness to policymakers and business owners.

- Advocating for the inclusion of the marginalized groups. Promoting video clips participatory made by the members of the marginalized groups on websites, social media platforms, and community media.

- Advocating for intercultural communication sessions on community media programs.

- Advocating for a clean and safe environment to work and to live by producing video clips or writing articles in both traditional and new media.

- Advocating for recreation spaces in workplaces and community. Video clips can be shown and uploaded on websites.

\subsubsection{Communication Strategies to Tackle Local Major Health Challenges of Noncommunicable Diseases, Injuries, and Violence}

Communication strategies aiming at an individual level are the following:

- Promoting eating right and exercising right by using video clips, messages, interpersonal contacts, and social networking sites. 
- Raising the awareness of monitoring weight, blood pressure, blood sugar, and blood cholesterol by a concert of campaigns and social marketing by using the new media.

- Promoting nonviolent solutions and gender respect with interpersonal communication and new media communication.

- Promoting the knowledge of noncommunicable diseases such as type 2 diabetes mellitus, heart infarct, coronary diseases, etc. by using print media, electronic media, new media, and interpersonal media.

- Engaging the stakeholders in a community to obey the traffic rules by encouraging them to report the violators in a social media site of the community.

Communication strategies aiming at a group level are as follows:

- Empowering the stakeholders to form peer-to-peer and support groups on any noncommunicable disease triggers such as smoking, lacking exercise, etc.

- Advocating for primary health-care units to monitor noncommunicable diseases with the collaboration of public health officials, the private sectors, and the civil society.

- Empowering for first aid courses at workplace, schools, and community.

- Advocating for a school-based training/education on noncommunicable diseases.

Communication strategies aiming at a structural level are the following:

- Advocating for poverty reduction to reduce mental health problems among multiple sectors. Personal media together with video clips or digital storytelling are to solicit support from policymakers.

- Advocating for the reduction of salt, sugar, trans fat, and saturated fat in processed food. This can be done with MPs, authorities, civil groups, and consumer groups.

- Advocating for monitoring, control, and penalties of pesticides and insecticides in fresh produce; and hormones, antibiotics, heavy metals, and other chemicals in meat, poultry, fresh water fish, and seafood.

- Advocating for stronger penalties for gender-based violence, including sexual harassment, and traffic rule violators.

\subsubsection{To Tackle Vaccine-Preventable Communicable Diseases}

In order to tackle vaccine-preventable communication diseases at an individual level, mass communication and various forms of community media can be employed to raise awareness. URL links to online information can be provided to share information on new vaccines and vaccines that bridge communicable and noncommunicable diseases such as Hepatitis B and human papillomavirus.

At a group level, advocating on any collaboration among risk groups and authorities by using participatory videos. Develop a surveillance and early-warning 
system in a community and monitor the outbreaks of diseases and keep the stakeholders informed by new media, traditional media, and interpersonal media.

At a structural level, advocating contacts with international organizations on sharing vaccine-preventable epidemiological data, laboratory data, evidence-based and cost-effective interventions, etc. Mobilizing for social support across the board. This includes lobbying for law enforcement on every childhood vaccination, subsidies for vaccination, food and water safety, etc.

\subsubsection{Communication Strategies to Tackle Non-vaccine- Preventable or Not-Yet-Vaccine-Available Communicable Diseases Such as Malaria, Dengue Fever, Tuberculosis (TB), and HIV/AIDS and Respiratory Diseases Such as SARS, MERS, H1N1, and H5N1}

Communication strategies aiming at an individual level are as follows:

- Advocating via the social and community media to emphasize the cause of the disease, the transmission, symptoms, and prevention of the disease.

- Empowering the stakeholders via personal media and community media campaigns, complemented by training courses of how important the sanitary and hygienic environment is in preventing some vector-borne diseases such as malaria and dengue fever and airborne diseases such as SARS.

- Participatory videos, digital storytelling, podcasts, and vodcasts can be uploaded to promote better education. Better education implies better occupation and thus better HIV prevention as HIV prevalence is partly related to poverty and low socioeconomic status.

- Using participatory community media to promote HIV counseling and testing, especially to mothers to be.

Communication strategies aiming at a group level are as follows:

- Advocating for an early warning and surveillance system for vector- and airborne diseases via the community media, new media, and traditional media.

- Use participatory short film of video to advocate the government for multisectoral collaboration, and raise funds to provide budget for bed nets in case of vector-borne diseases and budgets for helping dwellers in crowded and substandard housing to prevent airborne diseases.

- Empowering the stakeholders to support outreach and peer education activities by community and personal media.

- Social marketing by using the mass media, social media, and community media on anti-discrimination against people living with HIV/AIDS. Use personal media to include the people living with HIV/AIDS in community forums and activities.

- Advocating school-based interventions to teach students about hygiene, respiratory diseases, HIV/AIDS, TB, malaria, and dengue fever. 
- Empowering the stakeholders to take the mosquito-free environment and clean environment in their own hands.

Communication strategies aiming at a structural level are as follows:

- Using the mass media to gain social support on HIV/AIDS prevention in sex education curricula. Gender education should be done in a way of role plays and brainstorming to emphasize gender respect and learn that violence toward females can lead to HIV transmission.

- Mobilize social supports for alcohol control, improving housing standard, etc. by using participatory films, clips, photos, or audio files.

- Using participatory new media to promote a political environment that supports access to antiretroviral therapy for people living with HIV and employment for them and promote a well-informed civil society and nongovernmental bodies.

- Using integrated media to promote the linkage and integration of national programs on HIV/AIDS prevention and malaria, TB, dengue fever, and airborne epidemic prevention with broader health and development agendas.

\subsubsection{Communication Strategies to Strengthen People-Centered Health Systems, Public Health Capacity, and Emergency Preparedness, Surveillance, and Response}

Communication strategies aiming at an individual level are as follows:

- Empowering the health-care professionals to produce participatory video or audio files to advocate better working conditions, social supports, and recognition.

- Engaging health-care professionals in dialogues and skill training to increase competencies in intercultural communication, fiscal and budget, decisionmaking, etc.

- Empowering the stakeholders with participatory media to let them take part in designing, implementing, and evaluating health policies and services.

- Integrated media can be used to empower patients to make informed decisions and/or shared decisions between health-care providers and the patients.

- Empowering the disables, the elderly, and people with chronic diseases with integrated media to advocate access and services for them.

Communication strategies aiming at a group level are as follows:

- Using community media and new media to advocate for quality in primary health care.

- Using integrated media to call for good governance and collaborating with other health-care services. The media can be used to engage the stakeholders in helping forming ideas for a people-centered health care. 
- Contacting all actors and stakeholders to discuss indicators for success of such a health care service.

Communication strategies aiming at a structural level are as follows:

- Using integrating participatory new media and mass media to advocate national strategies for developing public health services; assessing present public health laws; revising the laws, if needed; and evaluating partnerships for their effectiveness.

- Using participatory new media to mobilize public health workers, health-care providers, patients, and the public at large to solicit more funding to pay off the operating costs of the health-care services.

- Using participatory media to promote social support for capacity building and assess good governance and efficiency in sharing data and networking with accredited public health organizations abroad.

\subsubsection{Communication Strategies to Create Resilient Communities and Supportive Environments, Including a Healthy Physical Environment}

Communication strategies aiming at an individual level are as follows:

- Setting up forums to discuss online on participatory media or offline to engage stakeholders in the environmental management of their community.

- Empowering each person in the community to act as a citizen journalist on outbreaks of diseases and natural disasters by engaging them in the activities of sharing video clips and audio files discussions online and offline.

- Empowering individuals by integrated media to monitor climate change and conserving the natural habitats, including reporting on pollutions.

- Engaging the entire community by integrated mass media, community media, and new media to promote garbage management and recycles within the community.

- Empowering individuals to use bicycles instead of motor vehicles by using traditional social marketing and new media social marketing.

Communication strategies aiming at a group level are as follows:

- Offering new media platforms in a community operated by peers to discuss ways to help improve the environment.

- Advocating for safe water, standard sanitation, and clean energy by integrating the mass media, community media, and new media.

- Using new media social marketing to promote the surveillance and preparedness systems for extreme weather events and disease outbreaks.

- Using traditional and new community media to promote events and engage the community dwellers to see the importance of recycling and garbage separation. 
Communication strategies aiming at a structural level are as follows:

- Gaining social support on measures, policies, and strategies to monitor and mitigate climate change by using participatory media.

- Mobilizing social support on educational and awareness programs on biodiversity, ecology, and climate change by using participatory media.

- Mobilizing support for research and development on conservation of natural habitats by using integrating mass communication, community media, and new media.

All of these tangible strategies are just examples of how to reach sustainability in health. People can be empowered to take health- and environmental-related issues in their own hands to ensure capacity building and networking.

\subsection{Conclusion and Recommendations}

By now the reader should be familiar with health communication for sustainability. Thanks to the advances in information and communication technologies or ICT, we can engage the community by media convergence and multimodal digital communication. As the media are not the messages, health communicators should research the strengths and weaknesses in communities regarding health and environment and get to know the stakeholders in order to devise the right communication strategies to suit the needs of the community.

The World Health Organization (WHO) acknowledges the multidimensional nature of health, that health involves complete physical, mental, and social wellbeing and not just the absence of disease. Moreover, everyone has the right to maintain and enjoy the benefits of being healthy regardless of their socioeconomic-politico and religious status. That means everyone has the right to medical, psychological, and related knowledge necessary to attain health to the fullest capacity. The health inequality caused by unequal development should be attended to by each government. Each government should be responsible for the health of their population by providing appropriate health and social measures.

Three important notions can be drawn from the constitution of the WHO: that "rights to health care," "health inequality reduction," and "health for all" are essential to devise good communication strategies to achieve the health goal.

Health communication is no longer a top-down fashion commanding the public to listen and act. We need to consider the enabling environment that would influence the decision-making process, attitude, and health behavior of an individual. Empowerment and advocating are the two terms health communicators as social mobilizers should be acquainted to. In order to do that, a health communicator should possess empathy and intercultural communication skills, apart from being media literate and health literate. This requires training and work experience. Apart from knowing public health, journalism, and communication, a health communicator should also have good knowledge of sociology, anthropology, environmental science, and management. Thus, interdisciplinary training would be a plus for a health communicator. 


\section{References}

Babrow AS, Mattson M (2003) Theorizing about health communication. In: Thompson TL, Dorsey A, Miller KI, Parrott R (eds) Handbook of health communication. Lawrence Erlbaum Associates, New York/London, pp 263-284

Berrigan FJ (1979) Community communications. The role of community media in development. UNESCO, Paris

Carpentier N, Lie R, Servaes J (2012) Multitheoretical approaches to community media: capturing specificity and diversity. In: Fuller L (ed) The power of global community media. Palgrave Macmillan, New York (paperback), pp 219-236

Castells M (2013) Communication power. Oxford University Press, Oxford

Colle R (2003) Threads of development communication. In: Servaes J (ed) Approaches to development: studies on communication for development. UNESCO, Paris, pp 22-72

Cox R, Pezzullo P (2016) Environmental communication and the public sphere, 4th edn. Sage, Los Angelis

Craig RT (1999) Communication theory as a field. Commun Theory 9(2):119-161

Dunn HL (1977) What high level wellness means. Health Values 1(1):9-16

Fuchs C, Sandoval M (2015) The political economy of capitalist and alternative social media. In: Atton $\mathrm{C}$ (ed) The Routledge companion to alternative and community media. Routledge, London/New York

Galanti G (2008) Caring for patients from different cultures, 4th edn. University of Pennsylvania Press, Philadelphia

Hjarvard S (2013) The mediatization of culture and society. Routledge, London/New York

Irwin H (1989) Health communication: the research agenda. Media Inf Aust 54:32-40

James O (2007) Affluenza. How to be successful and stay sane. Vermilion, London

Janzen JM (2002) The social fabric of health: an introduction to medical anthropology. McGrawHill, Boston

Katz E, Lazarfeld PF (1955 - latest ed. 2017) Personal influence. Routledge, London

Lasswell HD (1948) The structure and function of communication in society. Harper \& Bros, New York

Lee K (2005) Global social change and health. In: Lee K, Collin J (eds) Global change and health. Open University Press/McGraw-Hill Education, New York, pp 13-27

Lemert C, Elliot A (2006) The new individualism. Routledge, London

Lupton D (1994) Toward the development of critical health communication praxis. Health Commun 6(1):55-67

Malikhao P (2012) Sex in the village. Culture, religion and HIV/AIDS in Thailand. Southbound \& Silkworm Publishers, Penang-Chiangmai

Malikhao P (2016) Effective health communication for sustainable development. NOVA Publishers, New York

Marchlewicz EH, Anderson OS, Dolinoy DC (2015) Early-life exposures and the epigenome. Interactions between nutrients and the environment. In: Ho E, Domann F (eds) Nutrition and epigenetics. CRC Press, London/New York, pp 3-52

Martin JN, Nakayama TK (2004) Intercultural communication in contexts. McGraw-Hill, Boston

Martin JN, Nakayama TK (2010) Intercultural communication in contexts $\left(5^{\text {th }}\right.$ ed.). McGraw-Hill, New York

Ministry of Social Affairs and Health, Finland (2013) Health in all policies. In: Leppo K, Ollila E, Pena S, Wismar M, Cook S (eds) Seizing opportunities, implementing policies. http://www. euro.who.int/_data/assets/pdf_file/0007/188809/Health-in-All-Policies-final.pdf. Accessed on December $1, \overline{20} 18$

Mirowsky J, Ross C, Reynolds J (2000) Link between social status and health status. In: Bird CE, Conrad P, Fremont AM (eds) Handbook of Medical Sociology. Prentice-Hall Inc, Upper Saddle River, pp 68-78 
Pollard TM (2008) Western diseases. An evolutionary perspective. Cambridge University Press, Cambridge

Rattle R (2010) Computing our way to paradise? The role of internet and communication Technologies in Sustainable Consumption and Globalization. Rowman \& Littlefield Publishers, Inc, New York

Ryan RM, Deci EL (2002) Overview of self-determination theory: an organismic dialectical perspective. In: Deci EL, Ryan RM (eds) Handbook of self-determination research. The University of Rochester Press, Rochester, pp 3-33

Sarafino EP (2006) Health psychology. Biopsychosocial interactions, 5th edn. John Wiley \& Sons, Inc, New York

Servaes J (1999) Communication for development: one world, multiple cultures, 1st edn. Hampton Press, Inc, Cresskill

Servaes J, Malikhao P (2010) Advocacy strategies for health communication. Public Relat Rev:42-49. https://doi.org/10.1016/j.pubrev.2009.08.017

Share J (2015) Media literacy is elementary. Teaching youth to critically read and create media, 2nd edn. Peter Lang, New York

Turow JW (2014) Media today, 5th edn. Routledge, New York/London

Twenge JM, Campbell WK (2010) The narcissism epidemic: living in the age of entitlement. ATRIA, New York

Wallington SF (2014) Health disparities research and practice. The role of language and health communication. In: Hamilton HE, Chou WS (eds) The Routledge handbook of language and health communication. Routledge, London-New York, pp 168-183

World Health Organization Regional Office for Europe (2013) A European policy framework and strategy for the $21^{\text {st }}$ century. World Health Organization (WHO) Regional Office for Europe, Copenhagen

\section{Websites}

Center for Disease Control and Prevention (CDC) (2010) http://www.cdc.gov/h1n1flu/cdcresponse. htm. Accessed 18 Aug 2018

Center for Disease Control and Prevention (CDC) (2014) http://www.cdc.gov/flu/avianflu/h7n9virus.htm. Accessed 18 Aug 2018

Emedicinehealth.com (2018) https://www.emedicinehealth.com/mad_cow_disease_and_variant creutzfeldt-jakob/article_em.htm. Accessed 18 Aug 2018

The College of Physicians of Philadelphia (2018) https://www.historyofvaccines.org/content/arti cles/disease-eradication. Accessed 18 Aug 2018

World Health Organization (2018a) http://www.who.int/about/mission/en/. Accessed 21 Aug 2018

World Health Organization (2018b) http://www.who.int/tb/people_and_communities/advocacy_ communication/en/. Accessed 21 Aug 2018 